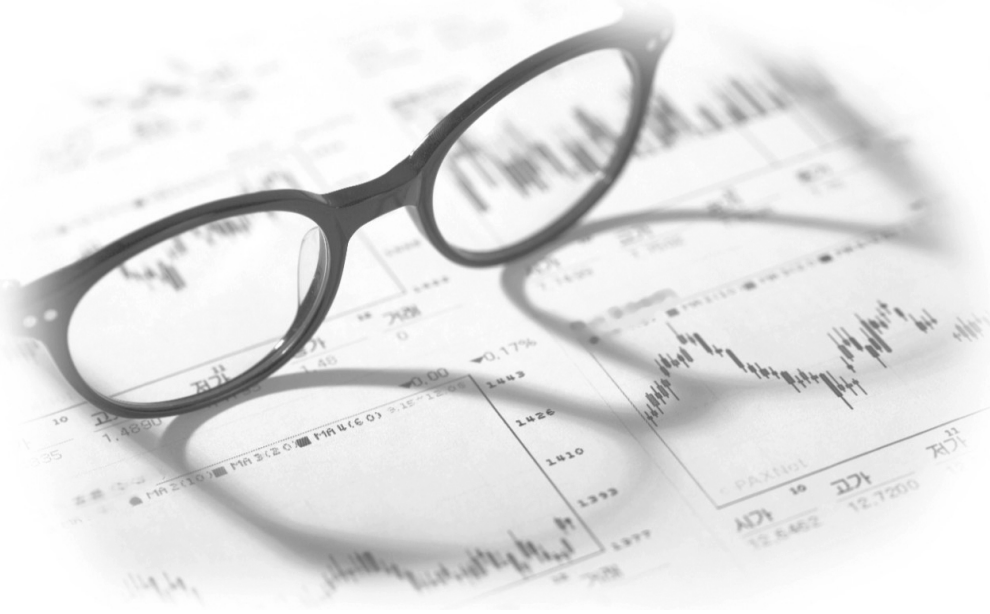

DOI: $10.5045 / \mathrm{kjh} .2010 .45 .4 .217$

The Korean Journal of Hematology Volume 45 • Number 4 • December 2010 Perspective

\section{What do patients want from the National Health Insurance?}

\author{
Seo Sun Won, Secretary-General, \\ Hee Young Shin, M.D. Board of Directors
}

\section{Korea Childhood Leukemia Foundation, Seoul, Korea}

\section{INTRODUCTION}

We are living in a society of increasing competition and as a result, the gap between the rich and poor has been widened. In this society, the ideal model of the advanced welfare state would be the one that could help people in their crises before they fall into a class of extreme poverty. Cancer, for example, is difficult to deal with by any individual due to its expensive and long-term management, and this can be a huge risk factor in family economy which can lead to a crisis. In this aspect, the national health insurance (NHI) could be considered as a great policy that pays for the medical fees, which helps and protects patients and families from high medical bills.

Korean NHI has become an important means of maintaining national health care, where the government operates the system with its own budget in addition to health insurance fees collected from people. Although our health insurance system started mostly based on Japanese national health insurance system, it is regarded as a highly beneficial policy that covers all people, providing high quality medical services with less cost.

\section{CONFLICTS BETWEEN HEALTH INSURANCE, HOSPITAL, AND PATIENTS}

Some people prepare for the risk of cancer through private commercial health insurance, however, most of the people generally have to be dependent on the NHI for cancer treatment. But, this support alone does not resolve the economic problems faced by patients and families. There are still many effective cancer treatments, which have not been reimbursed by the NHI.

As sometimes reported by media, many problems posed on patient's family come from the financial problems caused by these non-reimbursement treatments. In these situations, conflicts between the NHI, hospital, and patient's family are inevitable. Hospital claims that a treatment which has been proven to be effective in developed countries should be applied for better results of treatment, even if such treatment cannot be reimbursed. However, the NHI claims that hospital is performing unnecessary treatment for profit of the hospital, and considers it as an over-practice. On the other hand, patient and family claim that they are unreasonably burdened when the effective medical service is not reimbursed. Sometimes the patients file comments and complaints about the insurance system even once they decided to receive non-reimbursement treatments.

\section{NEED FOR A COMPREHENSIVE AND UNIFORMED TREATMENT PROTOCOL}

The most important matter for the patient is to recover from the disease. It would be acceptable, if the patient could be cured only by the treatments approved by the NHI. However, the patient would be devastated if he or she chose a reimbursement treatment instead of non-reimbursement treatment and the result was poor. Thus, patient's family tends to choose the treatment option that can be more beneficial to the patient regardless of the cost.

This is an Open Access article distributed under the terms of the Creative Commons Attribution Non-Commercial License (http://creativecommons.org/licenses/by-nc/3.0) which permits unrestricted non-commercial use, distribution, and reproduction in any medium, provided the original work is properly cited. 
Most people will trust and follow hospitals and doctors, if they recommend the best treatment options to patients without considering the profit. However, since that may not be always the case in reality, patients and families have difficulties in selecting the method of treatment and they may build distrust towards hospitals and doctors.

In bottom line, the patient and family want the Health Insurance Review and Assessment Service to provide them with a uniformed treatment protocol that could easily help them in choosing the best possible treatment options at times of tough decisions. Such a protocol exists today, but its standard of level seems so low that there is a concern for the low quality of medical service. It is now time that an upgraded uniformed treatment protocol apt with our standard of living is needed. Since the clinical conditions of patients are so diverse, a uniformed treatment protocol could not be applied in some cases. Such exceptional cases can be left to doctors' discretion. For all other general cases, national insurance should do its role allowing patients to receive the best medical service according to the upgraded uniformed treatment protocol.

If a new treatment option that is not included in the protocol is effective, patients and families would want to be treated by the new treatment regardless of the cost. Thus, there should be a legal policy to guarantee that the new treatment would not become illegal. Doctor's enthusiastic mind to cure the disease should be encouraged and medical approach towards the new treatment should not be withered.

\section{NEED FOR EXPANSION OF SUPPORT BY NATIONAL HEALTH INSURANCE}

The incidence of pediatric cancer is about 13 per 100,000 of population, and 1,200 children with age of under 15 years become new pediatric cancer patients every year in Korea. Leukemia is the most frequent disease that comprises
$40 \%$ of all pediatric cancers, and it requires about 2 to 3 years of long-term treatment. Not only the direct cost for the treatment is a burden, but extra costs (transportation cost, food, sanitation related costs, and etc.) that are spent in addition to the treatment is also very high, and in fact, many patients' families appeal for supports in those costs. According to the analyses of Korean National Cancer Registry data and the NHI data by National Cancer Management Project Team from National Cancer Center, a total of 478,446 cancer patients visited hospitals in 2005 and spent 2.3 trillion won as a medical cost, 900 billion won as a private nursing, transportation, and alternative treatment.

Korea Childhood Leukemia Foundation (KCLF) supports direct treatment cost as well as extra costs and living expenses. In 2009, we supported a total of 1,523,922,602 won, and extra cost support was $173,258,820$ won comprising $11.4 \%$. If the burden of direct treatment cost could be reduced by the expansion of support from the NHI, private fund like KCLF could then contribute more to support extra costs as well as costs for cancer treatment complication and for mental support projects that could help enhance the quality of lives of patients and families.

\section{CONCLUSION}

Every patient wants effective treatment and complete recovery from the disease. Organized system between the NHI, hospitals, and medical staffs is in need. The preparation of extensive and comprehensive treatment protocol and the expansion of health insurance support would help reduce the economic burden caused by diseases including cancer. Every person's life is sacred, and everyone has a right to live a healthy life. More systematic and rational policy is needed to maintain healthy lives, and this enhanced system will not only resolve the crises of patients, but will be a vital force that could keep our families and our society to stay healthy. 